\title{
La composición histórica de la educación religiosa como componente curricular
}

\author{
Sérgio Rogério Junqueira Azevedo ${ }^{1}$
}

Data da recebido: 02 de julho de 2013

Data da avaliação: 14 de agosto de 2013

Data de adopção: 19 de setembro de 2013
Esto creo

se debe pasar

a español

\author{
Esto estaba \\ en la parte \\ de portugués \\ pero creo debe ir \\ en este lugar, \\ según la secuencia \\ de la revista
}

\section{Resumen}

Este artículo es fruto de la investigación cualitativa de la historia de las disciplinas orientadas a la comprensión del desarrollo de una nueva concepción de la educación religiosa para el sistema educativo brasileño, que requiere una reorganización de la formación docente, el desarrollo de las subvenciones. Para entender este camino de cambiar el diseño de la educación religiosa del Brasil se estableció el contexto religioso y la política educativa del país. A partir de estos elementos se reconstruyó la historia de la disciplina teniendo en cuenta los diferentes períodos de la formación nacional. Mientras que los componentes del plan de estudios se caracterizan por el dominio de su propia lengua, entender los fenómenos de su área, promover la construcción de argumentos, contribuyendo así con el estudiante para enfrentar las situaciones más diversas, por lo que saber para preparar propuestas. Creemos que este texto permitirá una comprensión global de la formación pedagógica de la educación religiosa en un país culturalmente diverso.

\section{Palabras Clave}

Educación, enseñanza religiosa, historia de la enseñanza religiosa.

1 Doutor e Mestre em Ciências da Educação da Universidade Pontifícia Católica Salesiana (Roma, Itália), Licenciado em Pedagogia na Universidade de Uberaba. Líder do Grupo de Pesquisa Educação e Religião (www.gper.com.br), ex-Vice-Diretor da Associação de Educação Católica do Paraná, ex-Assessor da Conferência Nacional dos Bispos do Brasil na área do Ensino Religioso. Professor Titular da Pontifícia Universidade Católica do Paraná, Livre Docente e Pós-Doutor em Ciência da Religião na Pontifícia Universidade Católica de São Paulo. Correo: srjunq@gmail.com. 


\title{
The historical composition of religious education as a curricular component
}

\begin{abstract}
This article is the result of a qualitative research of the history of disciplines oriented to the understanding of the development of a new conception of religious education for the Brazilian educational system, that requires a reorganization of teacher training, the development of grants. To understand this path of changing the design of Brazil's religious education the religious context and education policy of the country was established. From these elements the history of the discipline was rebuilt taking into account the different periods of national formation. While the components of the plan of studies are characterized by the mastery of their own language, understanding the phenomena of its area, promoting argument construction, thus contributing with the student to face the most diverse situations, what to know to prepare proposals. We believe this article will enable a global understanding of pedagogical formation of religious education in a culturally diverse country.
\end{abstract}

\section{Keywords}

Education, religious education, history of religious education. 
Este texto

en Word

aparecía antes

del titular:

La composición

histórica de la

educación

religiosa como

componente

curricular.

Pero por el orden

que llevamos:

Español -Inglés

y por último

Portugués.

Debe ir en

este lugar.

Esto debe

continuar inmediatamente

después

de KeyWords

pero al dejarlo

en la página

anterior sólo cabría el título y el subtítulo y no queda bien, por eso toca iniciar en esta página.

\section{A composição histórica do ensino religioso como componente curricular ${ }^{2}$}

\section{Resumo}

Este artigo é uma pesquisa qualitativa documental a partir da história das disciplinas visando compreender o estabelecimento de uma nova concepção do ensino religioso para o sistema educacional brasileiro que exigiu um uma reorganização da formação de professores, elaboração de subsídios. Para compreender este percurso de alteração da concepção do ensino religioso brasileiro estabelecemos o contexto religioso e político educacional do páis. A partir destes elementos foi reconstruída a história da disciplina considerando os diferentes períodos da formação nacional. Considerando que os componentes curriculares são caracterizados por dominar sua própria linguagem, compreender os fenômenos de sua área, promover a construção de argumentos, contribuindo assim para o aluno para enfrentar as mais diversas situações e, portanto, saber para preparar as propostas. Acreditamos que este texto permitirá uma ampla compreensão da formação pedagógica do Ensino Religioso em um país culturalmente diverso.

\section{Palavra chave}

Educação, Ensino religioso, História do ensino religioso

\section{Introdução}

A disciplina do Ensino Religioso no Brasil, um país de dimensões continentais foi organizada para atender a duas estruturas de escolas, a pública mantida pelo governo (municipal e estadual) e as instituições escolares privadas especialmente as religiosas. Em decorrência desta diferenciação este componente curricular foi estabelecido

2 Artículo de reflexión que se enmarca en la investigación sobre Educación Religiosa y Formación Docente de la Universidad Pontificia Católica de Paraná (Brasil). La investigación se orienta hacia el método cualitativo de la historia de las disciplinas orientadas a la comprensión del desarrollo de una nueva concepción de la educación religiosa para el sistema educativo brasileño y fue financiada por la misma Universidad Católica de Paraná. 
com perspectivas adequadas a cada modelo de escola, porém a partir da segunda metade do século XX o país deparou-se com uma nova realidade no âmbito religioso, o crescimento de movimentos religiosos, cristãos e não cristãos que, progressivamente, mudaram a face religiosa nacional (Filho, 2008, pp. 83-85). Este fenômeno de crescimento de outras religiões ocorreu nas mais diferentes regiões latino-americanas e, especialmente, no Brasil cuja heterogeneidade religiosa é uma forte marca na configuração de seu povo, desde sua origem histórica do Século XVI. Além da própria colonização, outro fato relevante, foi o acordo político religioso entre as Coroas Portuguesa e Espanhola com a Igreja Católica Apostólica Romana, chamado de Padroado que garantiu o predomínio e a hegemonia católica no pais. Por conta disso e de outras mudanças, inclusive políticas, como por exemplo o país ter sido colônia portuguesa, ter se tornado império, e deste à república que no século XXI tem discutido e refletido a respeito desta pluralidade religiosa através da Educação Escolar nas instituições públicas e privadas, fundado num componente do currículo escolar que realiza o estudo das manifestações religiosas. Especialmente a partir da Constituição de 1988 que confirmou ser este país uma Republica Federativa que garante a liberdade religiosa, reafirmando ser um estado laico (Fracaro y Junqueira, 2009, pp. 14-16).

\section{Diversidade Religiosa do Brasil}

Visando compreender as opções pedagógicas e de conteúdo do Ensino Religioso brasileiro é importante contextualizar o cenário religioso do país, especialmente considerando o Censo demográfico do ano de 2010 o qual evidenciou a atual realidade nacional. Dentre os diversos aspectos pesquisados, dedicaremos a nossa atenção para a realidade religiosa.

Dados oficiais afirmam que o Catolicismo foi a religião da maioria do povo brasileiro durante décadas, porém um dado surpreendente não é só o crescimento de novas tradições religiosas, mas o contínuo crescimento dos que se declaram sem religião. No censo de 1991, eram de 4,7\%, em 2000 confirmaram 7,28\%, em 2010 o número indicado é de 8,0\% (15 milhões de brasileiros), ou seja, percebe-se um crescente aumento deste grupo. Não significa que essas pessoas sejam ateias, mas que encontram fora da instituição religiosa um novo espaço para viverem suas convicções religiosas (IBGE, 2010, Tabela 14, p. 1).

Historicamente, no Brasil, está ocorrendo um distanciamento entre o catolicismo nominal ou cultural do catolicismo praticante; a redução dos fiéis encontra-se, 
provavelmente, no primeiro grupo. Em pesquisas paralelas ao Censo, existe uma constatação: os indivíduos possuem práticas e devoções religiosas que não são necessariamente idênticas às institucionais. Muitos encontram nos movimentos e igrejas neopentecostais um acolhimento e uma metodologia que respondem a perguntas e resolvem a problemas imediatos e concretos do dia a dia. De forma acentuada, são as classes menos favorecidas economicamente que, pelas perdas sociais sofridas (terra, moradia, emprego, educação, saúde...), geram um processo de perda de identidade, de desenraizamento cultural e desequilíbrio emocional e que encontram nesses movimentos e Igrejas um reequilíbrio e uma ressignificação do seu cotidiano (Neri, 2011, pp. 07-08).

A força destes movimentos e igrejas aparentemente provém da crise do homem moderno que vive preso a um humanismo centrado no individualismo, despojado de realidades transcendentes, e que se relaciona com o transcendente a partir da ótica da econocracia. Este tipo de relação faz as pessoas procurarem as instituições religiosas, na maioria das vezes, somente no momento de aflição e sofrimento, o que revela a necessidade do fiel ter um lugar seguro para vivenciar a sua crença.

A cultura do individualismo, por destacar a autonomia e o proveito do individuo em detrimento do grupo, da sociedade ou da nação, gera nas pessoas um modelo ético flexível onde à medida ética seja o individuo e suas necessidades. Este modelo é transposto para o transcendente, daí os fiéis procurarem movimentos religiosos e ou igrejas onde as exigências éticas e morais foram flexibilizadas, e o sagrado adequou-se às exigências do mundo globalizado. Daí se explicar o crescimento de pessoas que se declaram "sem religião" por 3 fatores: pela prática não comprometida da religião católica; pela miscigenação cultural e religiosa; e pela busca de religiões que facilitem o culto, cenário bastante diferente de trinta anos atrás, quando a identidade católica era hegemônica, neste país.

Portanto, o catolicismo brasileiro atravessa um momento histórico de perda de hegemonia, ditada, sobretudo, pela modernidade, que não suprime o religioso, mas o transforma continuamente num processo de recomposição e perdas, onde homens e mulheres refazem seus sistemas de significados. Existe uma reestruturação das crenças e o surgimento de novas propostas religiosas.

Um dos desafios do catolicismo são a abertura e o reconhecimento dessas sensibilidades religiosas e a capacidade de reestruturação de sua própria linguagem e prática pastoral (Alves, 2009, pp. 20-21).

Quanto ao crescimento dos evangélicos, está associado a esta nova realidade social, fundada fortemente no individualismo e que exige das instituições um 
caráter mais móvel e pouco dogmático, visando a responder a necessidades objetivas, seja de ordem espiritual, material ou emocional. Uma parcela considerável dos novos evangélicos é formada por jovens de boa formação educacional, relativamente bem situado economicamente e que se convertem mais por consequências sociais do que teológicas, pois muitos se tornam adeptos por causa de parentes ou amigos que se converteram primeiro. Essa conversão, mais social do que teológica, provoca também uma mobilidade muito grande destes convertidos nas igrejas, pois os mesmos trocam de denominações religiosas com a maior naturalidade e sem nenhum problema de ordem doutrinal (Neri, 2011, pp. 47-49).

Por mais que as experiências ecumênicas e de diálogo religioso ocorram no Brasil há muitos anos, percebe-se, atualmente, uma tendência de crescimento da intolerância religiosa, devido às características dos novos movimentos religiosos que, geralmente, se organizam ao redor das idéias de um líder carismático, que prioriza o crescimento imediato do seu movimento religioso, cuja preocupação gera nos convertidos a ideia de pertencerem a um grupo de eleitos, exclusivos e separados de todos os mortais comuns e do mundo, lugar em que o mal e o pecado imperam e que, por isso, precisa ser exorcizado.

Estes novos movimentos religiosos reforçam a questão da conversão, que consiste no repúdio de um mundo em favor de outro. Toda a linguagem religiosa a respeito da conversão gira em torno da morte, regeneração e ressurreição. As grandes experiências religiosas de conversão contam histórias de transe, êxtase e fugas temporárias que, na realidade, constituem trânsito pela morte e volta para a nova vida. Momento em que o convertido troca a liberdade e o prazer pela paz e a segurança, mas entre o novo e o velho não há uma ruptura total, no novo há elementos do velho, há resquícios das antigas crenças, apesar de estarem travestidas como novidade.

As pesquisas existentes no campo da identidade religiosa explicitam, cada vez mais, uma nova realidade, a de que uma parcela considerável de adeptos professa uma religião que não é a mesma da sua infância. São adeptos convertidos, muitos deles tendo experimentado sucessivas opções. Houve tempo em que a mudança de religião representava uma ruptura social e cultural, além da ruptura com a própria biografia, com adesão de novos valores, mudança de visão de mundo, adoção de novos modelos de conduta. A conversão era um drama pessoal e familiar, representava uma mudança drástica de vida. Atualmente, mudar de religião parece não comover ninguém, muda-se de religião com a mesma naturalidade que um consumidor muda de marca; o adepto religioso transformou-se numa espécie de consumidor religioso (Filho, 2008, pp. 46-49). 


\section{Formação Educacional do Brasil}

Na Constituição brasileira afirma-se que a educação é um direito de todos e dever do Estado e da família, será promovida e incentivada com a colaboração da sociedade visando o desenvolvimento da pessoa, seu preparo para o exercício da cidadania e sua qualificação para o trabalho (Constituição, Art. 205). A escolarização no país está organizada em dois grandes segmentos: a Educação básica que ocorre até aproximadamente os dezessete anos e o Ensino Superior voltado para formação profissional e os Estudos de Pós-Graduação (Cervi, 2005, pp. 34-36).

O Ensino Religioso é uma disciplina que ocorre apenas na Educação Básica e esta ocorre em três níveis. Inicialmente até os cinco anos que se denomina Educação Infantil, dos seis aos quatorze anos de idade como Ensino Fundamental, dos quinze aos dezoito anos no Ensino Médio. Os princípios destacados para esta educação são: o desenvolvimento da capacidade de aprender, tendo como meios básicos o pleno domínio da leitura, da escrita e do cálculo; a compreensão do ambiente natural e social, do sistema político, da tecnologia, das artes e dos valores em que se fundamenta a sociedade; o desenvolvimento da capacidade de aprendizagem, tendo em vista a aquisição de conhecimentos e habilidades e a formação de atitudes e valores; o fortalecimento dos vínculos de família, dos laços de solidariedade humana e de tolerância recíproca em que se assenta a vida social (Lei 9.394/96, art. 32), e nisto o Ensino Religioso contribui sobremaneira.

A Educação brasileira está comportas por dois tipos de escolas, o primeiro são as instituições públicas, criadas, incorporadas, mantidas e administradas pelo poder público e as instituições privadas, que são mantidas e administradas por pessoas físicas ou jurídicas de direito privado (Lei de Educação de 1996 - 9.394/96, art. 19). No segundo grupo de escolas encontram-se as Instituições Confessionais que são instituídas por grupos de pessoas físicas ou por instituições de direito privado que atendem a orientação confessional e ideologia específicas (Lei 9.394/96, art. 20). Visando compreender a inserção do Ensino Religioso no contexto educacional brasileiro é fundamental rever a construção histórica deste componente no currículo da escola pública brasileira. Esta distinção é significativa para compreender o desenvolvimento do Ensino Religioso na educação nacional (Cervi, 2005, pp. 69-73). 


\section{Formação do Ensino Religioso}

Desde a formação do Brasil, o Ensino Religioso sofreu um lento processo de alteração em conseqüência do desenvolvimento do Estado, de sua autocompreensão e, portanto, das opções políticas. Ao longo dos períodos do Colonialismo e do Império brasileiro (séculos XV a XIX), o ensino caracterizou-se como uma cristianização, por delegação pontifícia, justificando o poder estabelecido. A educação foi implantada e ministrada sob os auspícios dos jesuítas. 0 governo não intervinha diretamente como primeiro interessado, nem propôs uma filosofia educacional, pois competia aos religiosos, controlados pelo governo, organizar e fazer funcionar o processo de escolaridade.

A concepção de educação desta fase foi a humanista, que se caracterizava por ser individualista centrada nos valores propostos pelo Renascimento e por favorecer a ideologia reinante, empregando métodos tradicionais. 0 ensino da religião é questão de cumprimento dos acordos estabelecidos entre a Igreja Católica e o Monarca de Portugal, acordos que recebia o nome de "acordo do padroado" e que se constituía numa forma de compromisso entre a Igreja Romana e o Reino de Portugal. As leis, decretos e instruções, em geral, propunham em primeiro plano a evangelização dos gentios. 0 caráter disciplinador de toda Catequese concorreu para a transmissão de uma cultura que visava à adesão ao catolicismo (Oliveira et al., 2007, pp. 27-29).

Progressivamente o Estado, então ainda monárquico, ampliou o pequeno sistema educacional, com a criação de cursos do Ensino Superior como a Medicina e Cirurgia, bem como a Academia de Belas Artes. Não houve, porém, significativa evolução no ensino para as classes populares; enquanto para as classes mais abastadas criou-se: bibliotecas, imprensa, teatro e escolas especializadas. Nesta época o Ensino Religioso foi de caráter mais privativo e doméstico do que institucional. Parte dele acontecia por meio das Confrarias Religiosas que ajudaram a eliminar o hiato existente entre a cultura europeia e a cultura africana, o que acaba propiciando a efetivação do sincretismo religioso.

O projeto religioso da Educação não conflitou com o projeto político dos reis e da aristocracia; foi à fase da Educação sob a ótica religiosa. 0 que se praticou foi à evangelização, segundo os modelos da época, ou seja, a cristianização por delegação pontifícia, autoridade de Roma, como justificativa do poder estabelecido, em decorrência do regime de padroado.

Dessa forma, o que se desenvolveu como Ensino Religioso no país foi o ensino da religião católica, com o objetivo de evangelização dos gentios e catequese 
dos negros, conforme as exigências do acordo do padroado (Fracaro y Junqueira, 2009, pp. 18-21).

A manifestação de um esforço de escolarização da religião pode ser observada na lei de 15 de outubro de 1827, que regulamentava o inciso 32, do artigo 179, da Constituição Imperial, ou seja, a lei complementar, no seu artigo sexto. Mas ao longo do Império nasceu à ideia do respeito à diversidade da população. Em um projeto relativo à Constituição, Rui Barbosa propunha, em seu artigo primeiro, terceiro parágrafo, que às escolas mantidas pelo Estado não deveria ser imposta uma crença.

A partir da Proclamação da República, em 15 de novembro de 1889, as chamadas tendências secularizantes existentes no Império foram assumidas pelo novo regime, organizado a partir do ideário positivista que, no campo da educação, foi responsável pela defesa da escola leiga, gratuita, pública e obrigatória, rejeitando, portanto, a ideologia católica que exerceu o monopólio do ensino de caráter elitista.

Assiste-se, desde a primeira república, um confronto entre a Igreja e o Estado. A Constituição de 1891, o artigo 72, parágrafo 6, traz a seguinte disposição: "[...] será leigo o ensino ministrado nos estabelecimentos públicos", o que causou grandes celeumas, tanto que, nos anos seguintes, o Episcopado tomou posição de defesa em relação ao ensino da religião, como corolário da liberdade religiosa e liberdade de consciência (Oliveira et al., 2007, pp. 32-33).

Ao longo do período republicano a Igreja Católica no Brasil conseguiu articular novos acordos com o governo brasileiro e o Ensino Religioso passou a ser obrigatório para a escola, concedendo ao aluno o direito de opção da matrícula, desta forma o dispositivo constitucional outorgado garante o Ensino Religioso no sistema escolar, porém na prática, continuou a receber um tratamento que o discriminava e dava origem a muitos desafios de natureza pedagógica e administrativa.

Progressivamente iniciou-se o processo de busca da identidade do Ensino Religioso na escola, ocorrendo um esforço de renovação da prática pedagógica em relação a seu conteúdo, pois, até o momento, não havia clareza quanto ao seu papel específico no ambiente escolar (Figueiredo, 1995, pp. 12-15).

Esta busca desta identidade e redefinição do papel do Ensino Religioso na escola, ligada à discussão de sua manutenção em termos de legislação, foi de significativa importância no processo da revisão constitucional nos anos oitenta, quando do movimento de toda a sociedade brasileira em prol da Constituinte, que culminou com a promulgação da Constituição de 1988. 0 passo seguinte foi à definição do perfil da disciplina na Lei de Educação Nacional que orienta toda a educação brasileira prevendo orientação específica referente ao Ensino Religioso. 
A revisão do artigo 33 que ocorreu em 1997 com a Lei 9475/97 ao afirmar que o Ensino Religioso, de matrícula facultativa, é parte integrante da formação básica do cidadão e constitui disciplina dos horários normais das escolas públicas de Educação Básica, assegurado o respeito à diversidade cultural religiosa do Brasil, vedadas quaisquer formas de proselitismo e ainda que os sistemas de ensino regulamentarão os procedimentos para a definição dos conteúdos do Ensino Religioso e estabelecerão as normas para a habilitação e admissão dos professores. Complementando o fato de que os sistemas de ensino ouvirão entidade civil, constituída pelas diferentes denominações religiosas, para a definição dos conteúdos do Ensino Religioso.

Esta nova redação do artigo sobre o Ensino Religioso prioriza a leitura pedagógica do Ensino Religioso a partir dos princípios nacionais de educação prevista no artigo terceiro da Lei de Diretrizes de Educação que afirma os seguintes princípios: igualdade de condições para o acesso e permanência na escola; liberdade de aprender, ensinar, pesquisar e divulgar a cultura, o pensamento, a arte e o saber; pluralismo de idéias e de concepções pedagógicas; respeito à liberdade e apreço à tolerância; coexistência de instituições públicas e privadas. Porém, cada estado da federação tem a liberdade de, a partir desta legislação nacional, orientar a definição de conteúdo e do perfil de professor (Oliveira et al., 2007, pp. 53-56).

Após esta concepção para o Ensino Religioso nas instituições públicas ocorreu em 2008 a homologação de um Acordo entre a República Federativa do Brasil e a Igreja Católica Apostólica Romana (Santa Sé) que no artigo 11 menciona que a República Federativa do Brasil, em observância ao direito de liberdade religiosa, da diversidade cultural e da pluralidade confessional do País, respeita a importância do Ensino Religioso em vista da formação integral da pessoa. O Ensino Religioso, católico e de outras confissões religiosas, de matrícula facultativa, constitui disciplina dos horários normais das escolas públicas de Ensino Fundamental, para escolas públicas e particulares, assegurado o respeito à diversidade cultural religiosa do Brasil, em conformidade com a Constituição e as outras leis vigentes, sem qualquer forma de discriminação (Baldisseri y Filho, 2012, pp. 302-303).

\section{O contexto orienta uma opção}

A partir da construção histórica do Ensino Religioso como componente curricular é importante destacar o contexto para as Escolas Católicas brasileiras que 
possuem ampla liberdade de orientar a disciplina segundo suas diferentes concepções, especialmente pelo fato de que estas instituições escolares em sua grande maioria estão sob a orientação de Congregações Religiosas masculinas e femininas, sendo que, proporcionalmente poucas escolas são administradas pelo clero diocesano.

A presença das Congregações no ambiente educacional ampliou sua significância no período do final do século XIX e início do século XX que a expandiram por todo o território nacional. Porém cada período da educação brasileira as Congregações procuraram adequar as exigências do governo brasileiro, da comunidade e da Igreja (Moura, 2000, pp. 21-22).

Em 1996 o Brasil estabeleceu a sua nova legislação para o sistema educacional, exigindo uma reorganização de todos os componentes curriculares, incluindo o Ensino Religioso, tanto nas escolas públicas quanto das particulares e confessionais.

Os componentes curriculares compreendem dentre outras funções o domínio da linguagem (leitura, escrita, compreensão, etc.) no idioma nacional, compreender e considerar os fenômenos de seu entorno, construção da capacidade argumentativa, vindo a contribuir para que os alunos enfrentem as mais diversas situações de forma exitosa.

Assumir a importância desses componentes garante o acesso ao conhecimento produzido socialmente e constitui instrumentos para a socialização, cidadania, democrática, exercício e desempenho, para assim refutar ou reformular a distorção do conhecimento, as taxas de diferentes valores de dogmatismo. Este trabalho ocorreu a partir do trabalho de muitos professores e especialistas foi possível articular uma proposta pedagógica para o Ensino Religioso, a fim de torná-lo componente curricular, ou pelo menos aproximá-lo. Estes estudos e pesquisa foi articulado o modelo fenomenológico sendo estabelecido como referência em muitas escolas católicas do país.

Portanto, a estruturação do Ensino Religioso como componente pertinente ao contexto escolar é, na realidade, a resposta a um desafio configurado há mais de um século, o que exige ocupar-se de algumas variáveis que interferem em sua composição escolarizada. Uma premissa é a de que esta se tratando de uma disciplina escolar, de forma direta que acompanha a trajetória pedagógica do currículo escolar (Fracaro y Junqueira, 2009, pp. 29-33).

A nova legislação nacional para a Educação exigiu que o Ensino religioso considerasse alguns aspectos tais como: - a sociedade local, com sua pluralidade social e cultural, que, com conquistas e injustiças, promovem a formação das 
gerações; - as famílias dos alunos, com seus valores e limitações, expressam através de visões de mundo, práticas diversas de convivência; - que o sistema escolar, com sua filosofia, prioridades econômicas e opções pedagógicas; - que estruturam uma rede de relações internas horizontais e verticais de poder; - que se compreendesse o corpo discente com suas histórias de vida, gosto e desgostos, conhecimento e instabilidade própria da idade, recebendo, assim, além das influências de toda sorte oriundas do contexto da participação social; - considerando a vida religiosa concreta de cada grupo, com cultos, práticas e crenças; - métodos de socialização; - gerando um clima mais ou menos sereno de atuação; - outros elementos como as sistematizações pastorais e teológicas; - a autoridade expressa através de livros sagrados, normas, pessoas.

Em decorrência desses referenciais, há a tendência nas Escolas Católicas, nas públicas e nas privadas por um Ensino Religioso que contribua no aspecto da leitura das manifestações religiosas. Por religiosa se considera a qualidade do questionamento e da atitude com que a enfrentamos, uma vez que esse componente curricular trata o religioso como capacidade que vai além da superfície das coisas, acontecimentos, gestos, ritos, normas e formulações, para interpretar toda a realidade em profundidade crescente e atuar na sociedade de modo transformador e libertador.

Se a pretensão da Escola brasileira, católica ou não, é atuar além da superfície das coisas é significativo que se considere os estudos dos fenomenólogos da Religião. O homem é "naturaliter religiosus", portanto, a religião aparece como uma característica constante dos seres humanos, em todas as épocas. Dessa forma, o plano histórico revela concepções diferentes da divindade, assim como formas rituais e sistemas de crenças profundamente antagônicos. Todavia, para os fenomenólogos, isso não excluiria de maneira alguma a possibilidade de individuar aspectos constantes nestas manifestações (Martelli, 1995, pp. 58-62).

Em cada família e em cada comunidade religiosa estão em ação forças de conservação e de mudança, de repressão e de libertação, de autoritarismo e de serviço ao bem comum (Gruen, 1984, pp. 8-11). Há conflitos de poder mais numerosos do que se percebe à primeira vista, e é fácil imaginar como é complexo o jogo das relações que se dão não só dentro de cada um desses espaços, mas ainda entre eles, afetando assim a política educacional para a formatação do Ensino Religioso.

O que se pretende não é uma oposição, nem dualismo, nem mera identificação; mas a descoberta gradual do Fenômeno Religioso (Gruen, 1988, pp. 18-21). 0 importante é que o Ensino Religioso não permaneça somente em informações e 
curiosidades, mas alcance uma educação para ação transformadora (Gruen, 1996, pp. 187-188).

Diante desse quadro, o Ensino Religioso assume o papel de provocar junto a cada um dos componentes da comunidade educativa o questionamento sobre a própria existência do humano participante destas intrincadas relações. Assim como favorece o conhecimento de diversas tradições religiosas responsáveis pela construção cultural do país, que inclui a Igreja Católica Apostólica Romana.

O modelo de Ensino Religioso fenomenológico propõe que o estudo desse componente curricular é o Fenômeno Religioso assumindo como compreensão do/de conceituação de Religião (lat.) "religio" como (lat.) "relegere" (port.) "reler", organizado por Cícero.

Esse filósofo propôs que "religio" é o culto aos deuses, segundo os costumes dos ancestrais e que a melhor religião é a mais antiga, porque está mais próxima dos deuses. Propôs também que é o conjunto de crenças e práticas tradicionais próprias a uma sociedade humana particular, que assim honra seus deuses e merece 0 respeito das demais comunidades. Um exemplo foi quando os romanos reconheceram aos judeus o direito de praticar livremente seu culto monoteísta a Javé em todo o Império. Foi concedido o estatuto jurídico de "religio licita". Compreendeu-se muito bem que esse termo "religio" poderia significar realidades religiosas bastante diferentes, mas qualificava sistemas com coerência de crenças e práticas enraizadas na cultura particular de um povo, e que esse conceito nada tem de exclusivo. Meslin (1992, pp. 78-80) aponta que é este sentido que E. Durkein retomou, dezoito séculos mais tarde, ao definir religião na qualidade de sociólogo, como um sistema solidário de crenças e práticas relativas a coisas sagradas.

Sendo que condições necessárias a uma correta compreensão do fenômeno religioso tais como o uso de um instrumento metodológico da maior isenção possível; a análise da constância de determinados valores ou credos ao longo do tempo; a utilização de documentos primários, leituras interculturais dos documentos primários, evitando qualquer tipo de classificação histórica ou sociológica e não incentivando a apropriação de causa-efeito na tentativa de explicar o momento fundamental do fenômeno religioso.

Compara-se o fenômeno religioso com o fenômeno social ou similar, podendo afirmar que a estrutura especial do homem é definida por um sistema de relações com os outros homens. Poder-se-ia descrever o fenômeno religioso como um mundo de estrutura estritamente relacional? Mas com o que ou com quem o homem se relaciona na religião? No fundo de toda a situação verdadeiramente religiosa, 
encontra-se a referência aos fundamentos últimos do homem: quanto à origem, quanto ao fim e quando à profundidade. 0 problema religioso toca o homem em sua raiz ontológica. Não se trata de fenômeno superficial, mas implica a pessoa como um todo. Pode caracterizar-se o religioso como zona do sentido da pessoa. Em outras palavras, a religião tem a ver com o sentido último da pessoa, da história, e do mundo (Oliveira, 2007, pp. 72-75).

A preocupação dos especialistas em estabelecer a compreensão etimológica dos termos utilizados na formatação do atual modelo foi o de favorecer a estruturação curricular do Ensino Religioso, sobretudo em um país com significativas diferenças culturais, que objetivamente interferem na operacionalização psicopedagógica da disciplina.

A partir destes referenciais foi proposto o seguinte objetivo para o Ensino Religioso: valorizar o pluralismo e a diversidade cultural presente na sociedade brasileira, facilitando a compreensão das formas que exprimem o Transcendente na superação da finitude humana e que determinam, subjacente, o processo histórico da humanidade. Por isso se necessita propiciar o conhecimento dos elementos básicos que compõem o fenômeno religioso, a partir das experiências religiosas percebidas no contexto do educando; para subsidiar o educando na formulação do questionamento existencial, em profundidade, para dar sua resposta devidamente informada; analisar o papel das tradições religiosas na estruturação e manutenção das diferentes culturas e manifestações socioculturais; facilitar a compreensão do significado das afirmações e verdades de fé das tradições religiosas; refletir o sentido da atitude moral, como conseqüência do fenômeno religioso e expressão da consciência e da resposta pessoal e comunitária do ser humano; possibilitar esclarecimentos sobre o direito à diferença na construção de estruturas religiosas que têm na liberdade o seu valor inalienável (Viesser, 2000, pp. 56-59).

Portanto, existe uma preocupação de apontar os aspectos informativos (ensino) e formativos (educação), por exemplo, como explicita Andrade (1993, pp. 69):

- informativo: ao indicar que sejam sistematizados, junto aos alunos, o conhecimento básico dos elementos do fenômeno religioso, estrutura e significado das diversas tradições religiosas;

- formativo: consideração do contexto de origem do aluno, a formulação do questionamento existencial do mesmo, as atitudes pessoais e comunitárias consequentes das manifestações religiosas e o direito inalienável de radiação religiosa. 
Os verbos propostos (propiciar, subsidiar, facilitar, e possibilitar) indicam a ação do professor sobre o aluno, apenas os verbos analisar e refletir apresenta o protagonismo do estudante. Mesmo diante desse limite semântico, existe um interesse para que o sujeito de todo o processo seja de fato a criança, o adolescente ou jovem que assume a sua história e procura relê-la na perspectiva do religioso. Diante de tal postura, é notório que os objetivos e o objeto proposto são consequências da reflexão, da compreensão e da intenção da disciplina.

A estrutura dos conteúdos que permitam operacionalizar esta proposta que é utilizada em algumas escolas católicas está organizada em cinco eixos:

a) Culturas e Tradições Religiosas: estudo do fenômeno religioso à luz da razão humana, analisando questões como: função e valores da tradição religiosa, relação entre tradição e ética, teodiceia, tradição religiosa natural e revelada, existência e destino do ser humano nas diferentes culturas;

b) Textos Sagrados (Orais e Escritos): textos que transmitem, conforme a fé dos seguidores, uma mensagem do Transcendente, através da qual, pela revelação, cada forma de afirmar o Transcendente faz conhecer aos seres humanos seus mistérios e sua vontade, dando origem às tradições. E estão ligados ao ensino, à pregação, à exortação e aos estudos eruditos;

c) Teologias: conjunto de afirmações e conhecimentos elaborados pelas religiões e repassados para os fiéis sobre o Transcendente, de um modo organizado ou sistematizado;

d) Ritos: série de práticas celebrativas das tradições religiosas formando um conjunto de rituais, símbolos e espiritualidades;

e) Ethos: forma interior da moral humana em que se realiza o próprio sentido do ser. É formado na percepção interior dos valores, através dos quais nasce o dever como expressão da consciência e como resposta do próprio "eu" pessoal. 0 valor moral tem ligação com um processo dinâmico da intimidade do ser humano e, para atingi-lo, não basta deter-se à superfície das ações humanas (Fracaro y Junqueira, 2009, pp. 12-15).

A partir desse quadro são propostos conteúdos relacionados às situações e acontecimentos do dia a dia e geradores de outros valores como a solidariedade, a honestidade, a justiça, a gratuidade, o senso da partilha, a esperança, a generosidade, a perseverança, a responsabilidade, a admiração, o amor, o respeito e outros. Também conteúdos que possibilitem uma relação consigo mesmo, com o outro, com o 
espaço e com o Transcendente, procurando despertar para a sensibilidade diante de situações desumanas, que ferem a dignidade humana, assim como perceber os mecanismos geradores de vida que devem ser valorizados, sobretudo os que proporcionam dignidade ao ser humano. Elementos que contribuam para a formação do senso crítico, de uma consciência ecológica, de uma síntese entre a cultura e a experiência religiosa.

Conteúdos que permitam compreender e reconhecer as diferentes denominações religiosas, os fundamentos antropológicos do simbolismo e sua relação com a experiência do transcendente. Elementos que habilitem o aluno uma leitura e interpretação dos fatos históricos e narrações relacionadas com o fenômeno religioso.

Para estabelecer a operacionalidade dos conteúdos e, sobretudo na perspectiva proposta, torna-se necessária uma retomada ao método fenomenológico que prevê brevemente os seguintes passos, conforme apontam Filorano e Prandi (1987, pp. 31-36): observação/ a experiência da manifestação; a compreensão da expressão observada e finalmente o testemunho ou a reflexão-partilha.

Esta proposição metodológica é coerente e facilmente se ajusta à estrutura de Projetos, que propicia um percurso muito interessante, pois dá ênfase ao que se quer ensinar em um currículo interdisciplinar (integração).

\section{Conclusões}

Como é possível perceber, existe uma diversidade de itinerários metodológicos que variam segundo a concepção de educar. Mas para aplicar a atual proposta do Ensino Religioso é necessário assumir um referencial metodológico e uma articulação de conteúdos na perspectiva de totalidade. Pois, se a escola pretende formar o cidadão consciente, precisa ajudar suas crianças na leitura da cultura de seu país, precisa ensiná-las a dar coerência ao mundo, isto é responsabilidade de todos; mas não se faz isso assim da noite para o dia e nem cada um isoladamente. Antes de tudo, é necessário articular as disciplinas, construir o texto escolar. Ser cada um capaz de realizar ações de integração. 


\section{Referências}

Alves, L. (2009). Cultura religiosa: Caminhos para a construção do conhecimento. Curitiba: Ibpex. Baldisseri, L., y Filho, I. (2012). Acordo Brasil-Santa Sé. São Paulo: Ltr.

Brasil (1988). Constituição da República Federativa do Brasil. Brasília: Senado da República Federativa do Brasil.

Brasil (1996). Leis e Diretrizes e Bases da Educação Nacional. Lei 9.394/96, de 20 dez. 1996. Estabelece as diretrizes e bases da educação nacional. Diário Oficial [da] República Federativa do Brasil, Brasília, DF, 134 (248), 27833-27841.

Brasil (1997). Revisão do Artigo 33 da LDB (9475/97). Brasília: MEC.

Cervi, R (2005). Padrão estrutural do sistema de ensino no Brasil. Curitiba: Ibpex.

Figueiredo, A. (1995). A. O ensino religioso no Brasil: tendências, conquistas e perspectivas. Petrópolis: Vozes.

Filho, S. (2008). Espaço Sagrado: Estudo em geografia da religião. Curitiba: Ibpex

Fracaro, E. y Junqueira, S. (2009). O Sagrado: Fundamentos e conteúdo do Ensino Religioso. Curitiba: Ibpex.

Gruen, W. (1984) Problemas do professor de Ensino Religioso. Revista de Catequese, 07(28), 5-12. Gruen, W. (1988). A natureza do Ensino Religioso à luz de uma aula. Revista de Catequese, 11 (44), 13- 25.

Gruen, W. (1996). Educação Religiosa - premissas. Revista Convergência, 31(291), 181-189. Instituto Brasileiro de Geografia e Estatística - IBGE (2011). Relatório final do Censo de 2010 - Tabela 14.1 População residente, por situação do domicilio e sexo, segundo os grupos de religião. Brasília: IBGE.

Junqueira, S. (2011). A construção histórica entre o Ensino Religioso e as Ciências da Religião no cenário brasileiro. In Oliveira, P y De Mori, G. (Ed.). Religião e Educação para a cidadania (pp. 169 a 188). São Paulo: Paulinas.

Martelli, S. (1995). A religião na sociedade pós-moderna. São Paulo: Paulinas.

Meslin, M. (1992). A experiência humana do divino: Fundamentos de uma antropologia religiosa. Petrópolis: Vozes.

Moura, L. (2000). A Educação católica no Brasil. São Paulo: Loyola.

Neri, M. (2011). Novo mapa das religiões. Rio de Janeiro: FGV/ CPS.

Oliveira, L et all (2007). Ensino Religioso no Ensino Fundamental. São Paulo: Cortez.

Viesser, L. (2000). Programa de Ensino Religioso. Curitiba: Fonaper.

Andrade, R. (1993) Metodologia do Ensino Religioso: Novas perspectivas. Revista de Educação AEC, 22(88), 69-78.

Filorano, G.y Prandi, C (1987). Le scienze delle religioni. Brescia Morcelliana. 
